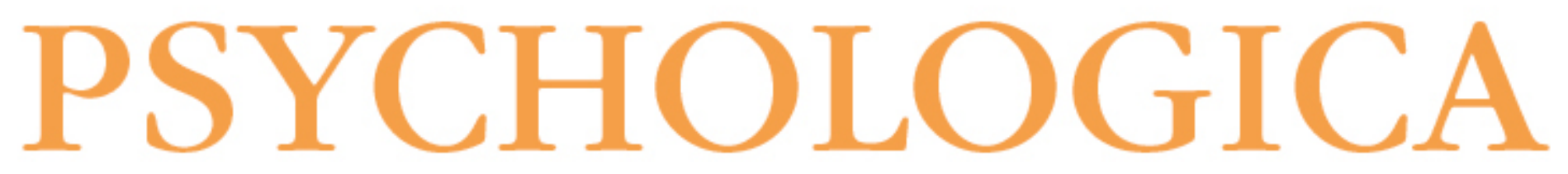

$O$ (in)sucesso na competição desportiva: a influência da aceitação e do autocriticismo

Autor(es): $\quad$ Gouveia, José Pinto; Xavier, Ana

Publicado por: Imprensa da Universidade de Coimbra

URL

persistente: URI:http://hdl.handle.net/10316.2/3476

DOI: DOI:http://dx.doi.org/10.14195/1647-8606_52-2_15

Accessed : $\quad$ 26-Apr-2023 16:29:57

A navegação consulta e descarregamento dos títulos inseridos nas Bibliotecas Digitais UC Digitalis, UC Pombalina e UC Impactum, pressupõem a aceitação plena e sem reservas dos Termos e Condições de Uso destas Bibliotecas Digitais, disponíveis em https://digitalis.uc.pt/pt-pt/termos.

Conforme exposto nos referidos Termos e Condições de Uso, o descarregamento de títulos de acesso restrito requer uma licença válida de autorização devendo o utilizador aceder ao(s) documento(s) a partir de um endereço de IP da instituição detentora da supramencionada licença.

Ao utilizador é apenas permitido o descarregamento para uso pessoal, pelo que o emprego do(s) título(s) descarregado(s) para outro fim, designadamente comercial, carece de autorização do respetivo autor ou editor da obra.

Na medida em que todas as obras da UC Digitalis se encontram protegidas pelo Código do Direito de Autor e Direitos Conexos e demais legislação aplicável, toda a cópia, parcial ou total, deste documento, nos casos em que é legalmente admitida, deverá conter ou fazer-se acompanhar por este aviso.

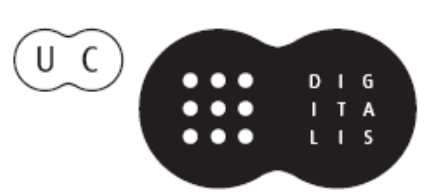




\section{NÚMERO 52}

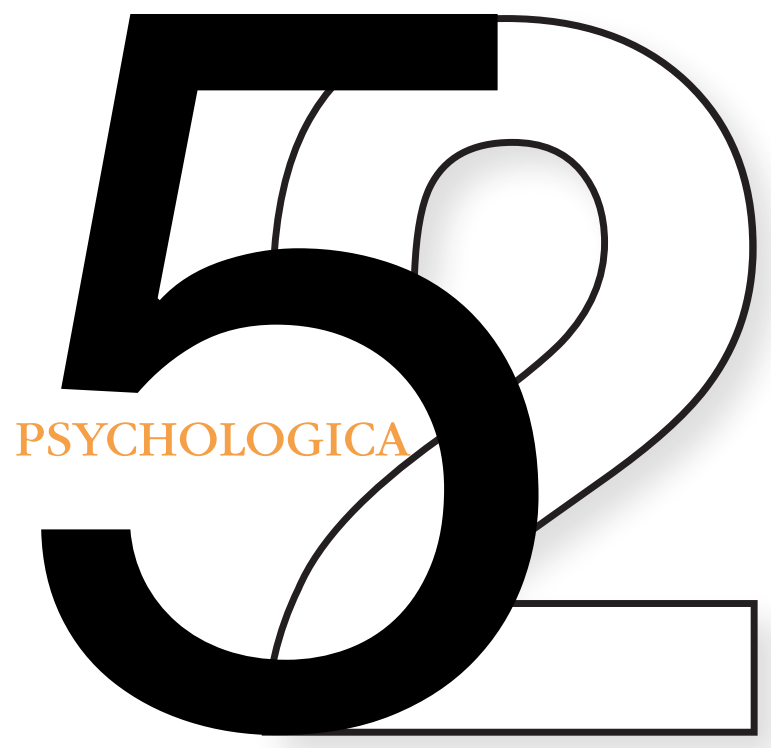

VOLUME II

IMPRENSA DA UNIVERSIDADE DE COIMBRA

FACULDADE DE PSICOLOGIA E DE CIÊNCIAS DA EDUCAÇÃo DA UNIVERSIDADE DE COIMBRA 


\title{
O (In)Sucesso na Competição Desportiva: A influência da Aceitação e do Auto-Criticismo
}

\author{
José Pinto Gouveia' \& Ana Xavier²
}

Tem sido evidenciada empiricamente a importância da aceitação dos acontecimentos privados (pensamentos, emoções, sensações), especialmente aqueles que são avaliados negativamente, como uma resposta contrária às tentativas de alterar, evitar ou controlar as experiências negativas cognitivas e afectivas, assim como ao auto-criticismo. O presente estudo analisa numa amostra de 106 atletas de natação, a influência da aceitação e do auto-criticismo na motivação dos atletas e na sintomatologia ansiosa e depressiva experienciada, nos diferentes momentos de antecipação, durante e de reacção à competição.

Os resultados mostram que a ansiedade competitiva se correlaciona negativamente com a aceitação e as competências psicológicas funcionais para o desporto. Além disso, a ansiedade competitiva apresenta correlações positivas com o auto-criticismo e a percepção de ameaça gerada pela competição. As análises de regressão mostram que a aceitação é o melhor preditor da ansiedade competitiva; o auto-criticismo é o melhor preditor da percepção de ameaça gerada pela competição.

PALAVRAS-CHAVE: Aceitação; Auto-Criticismo; Ansiedade Competitiva; Motivação.

\section{Introdução}

O desporto é um domínio da actividade humana capaz de elicitar uma ampla gama de emoções. Alegria e orgulho, vergonha e ansiedade, irritação ou raiva e culpa são exemplos de emoções comummente experienciadas pelos indivíduos que participam, de forma directa ou indirecta, na competição desportiva (Cruz, 1996).

Para além da vasta gama de emoções que o desporto pode gerar, é sabido que a experiência de stress e ansiedade na competição desportiva constitui um problema comum e preocupante para todos aqueles que, directa ou indirectamente, estão

\footnotetext{
1 Centro de Investigação do Núcleo de Estudos e Intervenção Cognitivo-Comportamental (CINEICC) Faculdade de Psicologia e de Ciências da Educação da Universidade de Coimbra - jpgouveia@fpce.uc.pt 2 Centro de Investigação do Núcleo de Estudos e Intervenção Cognitivo-Comportamental (CINEICC) Faculdade de Psicologia e de Ciências da Educação da Universidade de Coimbra.
} 
envolvidos no desporto (Cruz, 1996). Os dados de diversos estudos (Jones \& Hardy, 1990; Gould, Jackson \& Finch, 1993; Cruz, 1996; Barbosa \& Cruz, 1997) mostram uma elevada incidência de stress e ansiedade no desporto, experienciada por muitos atletas, independentemente da idade, sexo, nível competitivo ou modalidade. Enquanto para alguns indivíduos a competição constitui uma actividade agradável e desafiadora, para outros pode ser uma situação ameaçadora e até mesmo aversiva (Smith, 1980). Para alguns atletas os níveis de activação gerados pela prática desportiva são percepcionados como positivos e desafios às suas capacidades, ao passo que para outros essa activação é avaliada como ameaçadora e evitada de forma a não demonstrar fracasso ou falta de capacidade (Araújo \& Gomes, 2005). Com efeito, "o evitamento de actividades geradoras de stress impede o desenvolvimento de competências para lidar com o stress e a falta de competências que daí resulta fornece uma base realista para o medo" (Bandura, 1977, p.24).

A literatura da Psicologia do Desporto documenta não só o potencial impacto do stress e da ansiedade nas prestações desportivas, mas também a diversidade e inter-dependência de factores e processos psicológicos implicados no rendimento e no sucesso desportivo (Cruz, 1996). Os vários modelos conceptuais formulados para a ansiedade e o stress em contextos desportivos salientam a natureza multidimensional da Ansiedade Competitiva (Martens et al., 1983; Smith, 1986; Cruz, 1996; Cruz \& Barbosa, 1998; Cruz et al., 2006). Assim, a intensidade e a duração do estado de ansiedade competitiva são influenciadas pela natureza da situação competitiva e pelas características do próprio indivíduo, podendo implicar reacções cognitivas, emocionais e comportamentais (Cruz \& Barbosa, 1998). Existe alguma evidência empírica para o importante papel e influência do traço de ansiedade competitiva, quer nos estados de ansiedade competitiva, quer no comportamento, quer ainda, de forma menos clara, no rendimento (Cruz, 1996). Outros estudos sugerem que tanto ou mais importantes do que os níveis de stress e ansiedade experienciados na competição, são as competências de confronto e de lidar com o stress e a ansiedade possuídas pelos atletas (Mahoney, Gabriel, \& Perkins, 1987; Cruz, 1996).

Tradicionalmente a Psicologia do Desporto, com os seus esforços para aumentar o desempenho competitivo dos atletas, coloca a ênfase da intervenção no desenvolvimento do auto-controlo dos estados internos, utilizando técnicas e métodos cognitivos e comportamentais comummente referidos como Treino de Competências Psicológicas (Whelan, Mahoney \& Meyers, 1991; Gardner \& Moore, 2004). Em contraste com esta visão tradicional, os modelos mais recentes, que assentam na dicotomia Evitamento Experiencial/Aceitação, focam a importância da intervenção na redução do evitamento experiencial e na promoção da aceitação das experiências internas (pensamentos, sentimentos e sensações corporais). 
O Evitamento Experiencial é um fenómeno que ocorre quando o indivíduo não está disposto a permanecer em contacto com experiências privadas avaliadas negativamente (por exemplo, sensações corporais, emoções, pensamentos, memórias, imagens, predisposições comportamentais) e envolve-se em acções para alterar a forma ou a frequência dessas experiências ou dos contextos que as ocasionam, mesmo quando essas formas de evitamento causam dano comportamental (Hayes et al., 2004a; Hayes et al., 2006). Deste modo, a tentativa de controlar leva as pessoas a focarem-se mais no seu mundo interno (por exemplo, as emoções) como fonte adequada da regulação comportamental, o que vai conduzir ao exacerbar ainda mais os padrões de evitamento experiencial (Hayes et al., 2006).

Segundo Hayes, Strosahl, Wilson, Bisset e colaboradores (2004b), o Evitamento Experiencial per se é um processo e não uma teoria. O Evitamento Experiencial torna-se um processo desordenado quando é aplicado rígida e inflexivelmente como, por exemplo, quando são dedicados muito tempo, esforço e energia para lidar, controlar ou lutar com acontecimentos privados indesejados. Esta luta, por seu turno, diminui o contacto com experiências presentes. Paradoxalmente, a tentativa de esconder ou inibir pensamentos, sentimentos e sensações corporais indesejados serve para aumentar a frequência e intensidade destas mesmas experiências e consequentemente o sofrimento (Kashdan, Barrios, Forsyth, \& Steger, 2006). Assim, a relutância em permanecer em contacto com acontecimentos privados avaliados negativamente e a tentativa crónica para alterar a forma como esses acontecimentos ou circunstâncias surgem (experiências emocionais e psicológicas privadas, contendo intensidade, frequência e valência negativa), são fortes factores que contribuem para a psicopatologia (Kashdan et al., 2006).

Em amostras clínicas e não clínicas, o evitamento experiencial está fortemente correlacionado com medidas de psicopatologia geral (Hayes \& Feldman, 2004; Kashdan et al., 2006) e medidas específicas de ansiedade e depressão (Kashdan et al., 2006). Estudos (Feldner, Zvolensky, Eifert, \& Spira, 2003; Karekla, Forsyth, \& Kelly, 2004; Spira, Zvolensky, Eifert, \& Feldner, 2004; Kashdan et al., 2006) demonstram que o evitamento experiencial amplifica a sintomatologia ansiosa em indivíduos sem história de distúrbios ansiosos. Existe evidência de que o evitamento experiencial é um factor de vulnerabilidade para as perturbações de ansiedade e não apenas uma consequência das mesmas (Hayes \& Feldman, 2004; Kashdan et al., 2006).

O oposto do Evitamento Experiencial é designado por Aceitação Psicológica, que etimologicamente, significa "receber aquilo que é oferecido" (Mairal, 2004; Hayes, \& Smith, 2005, p.45). A Aceitação não deve ser confundida com tolerância ou resignação, pois ambos são passivos e fatalistas (Follette, Palm, \& Hall, 2004). Hayes (1994) define a aceitação como "permanecer em contacto com os 
estímulos funcionais directos ou automáticos dos acontecimentos, sem agir no sentido de os reduzir ou manipular" (pp.30-31). A aceitação envolve, então, três processos: (i) notar eventos privados que são experienciados, (ii) deixar de realizar esforços para evitar ou mudar esses eventos privados, e (iii) responder a acontecimentos actuais, em vez de responder a experiências privadas produzidas por aqueles acontecimentos. Assim, a aceitação envolve o abandono consciente de comportamentos que funcionam como evitamento experiencial, e a disposição para experienciar os pensamentos e as emoções tal como eles ocorrem (Follette, Palm, \& Hall, 2004). Em suma, a Aceitação envolve adoptar uma atitude consciente de não julgamento e aceitar activamente a experiência dos pensamentos, sentimentos e sensações corporais tal como eles ocorrem (Hayes et al., 2004a). A Aceitação é, então, ensinada como uma alternativa ao Evitamento Experiencial (Hayes et al., 2006).

Quando os indivíduos sofrem perturbações ou quando falham em certas tarefas (por exemplo, falhar em atingir um objectivo), eles podem temer ou recear as consequências (por exemplo, ser humilhado, rejeitado pelos outros), tornando-se auto-críticos e incapazes de aceder à auto-tranquilização e auto-reconforto do Eu (Gilbert \& Procter, 2006). O auto-criticismo ou auto-condenação, os sentimentos e as cognições de desvalorização pessoal, assim como uma relação interna hostil são comuns, podem surgir em múltiplas actividades e interacções sociais (Gilbert \& Irons, 2004, 2005) e estão subjacentes a muitas formas de dificuldades psicológicas (Gilbert \& Irons, 2005).

Segundo Gilbert, Clarke, Hempel, Miles, e Irons (2004), o Auto-Criticismo ocorre a um nível interno (Eu com o Eu), em que uma parte do Eu é crítica e dirige ameaças, enquanto a outra parte se submete e se sente derrotada. Assim, de acordo com uma perspectiva evolucionária, o auto-criticismo é uma forma de relação intrapessoal de dominância-submissão, onde uma parte do Eu encontra falhas, defeitos, acusando, condenando, culpando ou mesmo detestando a outra parte, activando no indivíduo estratégias defensivas de submissão (Gilbert, 2000; Gilbert \& Irons, 2005). Deste modo, os sentimentos e pensamentos auto-críticos podem ser encarados como formas de perseguição e hostilização internas, sendo forte fonte de stress (Gilbert et al., 2004).

Gilbert e colaboradores (2004) sugerem que o auto-criticismo não é um processo unidimensional, variando em termos de formas e funções ${ }^{3}$ distintas. Relativamente às formas, o auto-criticismo pode focar-se nos erros e sentido de inadequação perante fracassos e derrotas (“Eu inadequado"), querer magoar o Eu, eviden-

\footnotetext{
3 Os mesmos autores (Gilbert et al., 2004) subdividiram igualmente o auto-criticismo em diferentes funções, sendo que pode assumir uma função de auto-correcção (auto-aperfeiçoamento) e de autoperseguição (perseguir, vingar-se, magoar e atacar o Eu).
} 
ciando sentimentos de agressividade e ódio para com o mesmo ("Eu detestado"), ou dar relevo a aspectos positivos do Eu, adoptando uma atitude calorosa e de tranquilização dirigida ao Eu ("Eu tranquilizador"). A primeira e segunda forma do auto-criticismo relacionam-se positivamente com a depressão, enquanto a capacidade para se auto-tranquilizar ou auto-reconfortar relaciona-se de modo negativo com a depressão (Gilbert, Durrant \& McEwan, 2006).

Apesar do auto-criticismo ou auto-ataque ser tipicamente activado quando os indivíduos sentem que falharam em tarefas consideradas importantes ou quando "as coisas correm mal", uma resposta alternativa ao sentido de falha pode ser o auto-suporte ou compaixão dirigida ao Eu (por exemplo, enfatizar aquilo que se pode fazer para tranquilizar o Eu) (Gilbert et al., 2004). Assim, Gilbert (2000) tem sugerido recentemente a importância de ajudar os indivíduos a desenvolver calor interno dirigido ao Eu como uma resposta contrária à auto-repugnância e ódio.

Os dados (Gilbert, Baldwin, Irons, Baccus \& Palmer, 2006) mostram que aqueles que são auto-críticos, comparativamente àqueles que se auto-tranquilizam, estão em elevado risco de psicopatologia. Especificamente, os resultados (Gilbert et al., 2006) sugeriram que o traço de auto-criticismo está associado à facilidade em gerar imagens auto-críticas hostis e negativamente poderosas, ao passo que o traço de auto-tranquilização está relacionado com a facilidade em criar imagens de suporte e calorosas acerca do Eu. Além disso, as dificuldades em produzir imagens compassivas e de auto-tranquilização, com calor dirigido ao Eu, podem contribuir também para sintomas depressivos. Assim, os indivíduos auto-críticos podem sofrer devido não só aos elevados sentimentos negativos acerca do Eu, mas também à incapacidade de gerar imagens e sentimentos auto-reconfortantes dirigidos ao Eu.

Recentemente tem-se defendido e demonstrado o suporte empírico de intervenções que enfatizam a aceitação, como oposto às tentativas para mudar, suprimir ou controlar as experiências cognitivas e afectivas (Hayes, Strosahl \& Wilson, 1999; Segal, Williams \& Teasdale, 2002; Gardner \& Moore, 2004) e à atitude crítica e julgadora do Eu (Gilbert \& Irons, 2004).

Deste modo, as novas abordagens para aumentar o desempenho atlético tendem a incorporar estes dois aspectos (Gardner \& Moore, 2004). Gardner e Moore (2004) apresentam uma abordagem baseada no Mindfulness-Aceitação-Compromisso (do inglês, Mindfulness-Acceptance-Commitment (MAC), que enfatiza a atenção ao momento presente, mindful, e não-julgadora, e a aceitação de estados internos (tais como, pensamentos, sentimentos e sensações físicas) como experiências humanas naturais, bem como a disposição para permanecer em contacto com estados internos (notando a sua natureza e intensidade). Adicionalmente, o foco da atenção é colocado em pistas relacionadas com o desempenho (tarefa 
relevante), contingências e comportamentos contextuais apropriados ao serviço de objectivos atléticos valorizados (Gardner \& Moore, 2004).

Assim, baseados nas investigações recentes no domínio das variantes clínicas desta abordagem, Gardner e Moore (2004) hipotetizam que os atletas que receberem esta intervenção demonstrarão um aumento da consciência atencional e nãojulgadora, foco atencional na tarefa relevante e flexibilidade comportamental. Assim, espera-se que estes processos resultem num aperfeiçoamento da qualidade da prática/treino, do desempenho competitivo e aumento do prazer da experiência desportiva. Gardner e Moore (2004) aplicaram esta abordagem a dois atletas, o que fornece algum suporte inicial à hipótese de que a integração de técnicas de mindfulness, aceitação e compromisso podem ser aplicadas eficazmente à população de atletas com a finalidade de aumentar o desempenho competitivo.

A forma como o indivíduo se relaciona consigo próprio através de uma atitude de aceitação e de uma atitude crítica pode influenciar a sua reacção ou forma como responde ao sucesso e ao fracasso. Assim, o objectivo do presente estudo é fornecer um contributo para a compreensão do papel da aceitação/evitamento experiencial e do auto-criticismo no desempenho competitivo e na motivação dos atletas para treinar/competir após a percepção de sucesso ou fracasso. Mais especificamente, pretende-se avaliar a relação entre a aceitação psicológica, o auto-criticismo e diferentes constructos aplicados ao contexto desportivo, nomeadamente as competências psicológicas funcionais, a ansiedade competitiva e a percepção de ameaça gerada pela competição. Pretende-se ainda analisar a influência da aceitação na sintomatologia ansiosa e depressiva experienciada por atletas implicados num contexto que é, por si só, potencialmente gerador de elevados níveis de stress e ansiedade: a competição desportiva.

Nesse sentido, hipotetizamos que os indivíduos com níveis mais elevados de auto-criticismo tendem a experienciar mais sintomatologia ansiosa e depressiva, e a ficar menos motivados após a percepção de desempenho de fracasso na competição desportiva. Inversamente, os indivíduos com níveis mais elevados de aceitação tendem a experienciar menor sintomatologia ansiosa e depressiva, e a ficar mais motivados após a percepção de desempenho de fracasso na competição desportiva.

\section{Metodologia}

\subsection{Caracterização da Amostra}

A amostra foi constituida por um total de 106 atletas da modalidade de natação pura de competição, dos quais 65 são do sexo masculino (61.3\%) e 41 do sexo 
feminino (38.7\%), com idades a partir dos 16 anos, inclusive. No seu conjunto, a amostra de atletas inclui sujeitos de 16 clubes das zonas norte e centro de Portugal, que competiam em diferentes escalões competitivos (juvenil/júnior, sénior e master). No Quadro 1 estão representadas as características gerais da amostra.

Os participantes tinham uma média de idades de 18.35 ( $D P=6.46)$ para os homens e de $19.71(D P=8.13)$ para as mulheres, com uma média de anos de escolaridade de cerca 12 anos. No que respeita ao estudo das diferenças entre sexos, foram apenas encontradas diferenças estatisticamente significativas para o Escalão Competitivo $\left(\chi^{2}(2)=24.980 ; p=.000\right)$.

Quadro 1. Características gerais da amostra $(\mathrm{N}=106)$

\begin{tabular}{|c|c|c|c|c|c|c|}
\hline & \multicolumn{2}{|c|}{$\begin{array}{l}\text { Sexo Masculino } \\
(n=65)\end{array}$} & \multicolumn{2}{|c|}{$\begin{array}{c}\text { Sexo Feminino } \\
(n=41)\end{array}$} & \multirow[b]{2}{*}{$\mathrm{t}$} & \multirow[b]{2}{*}{$p$} \\
\hline & $M$ & $\mathrm{DP}$ & $M$ & $\mathrm{DP}$ & & \\
\hline Idade & 18.35 & 6.46 & 19.71 & 8.13 & -.949 & .345 \\
\hline Anos de Escolaridade & 11.71 & 1.79 & 11.71 & 1.85 & .001 & .999 \\
\hline Experiência/Anos de Prática & 12.46 & 4.95 & 11.49 & 3.05 & 1.131 & .261 \\
\hline Anos de Competição & 7.80 & 4.65 & 6.73 & 2.49 & 1.352 & .179 \\
\hline Horas de Treino por Semana & 16.02 & 5.12 & 14.76 & 5.66 & 1.184 & .239 \\
\hline \multirow[t]{2}{*}{ Competições por ano } & 17.83 & 5.59 & $17 \cdot 34$ & 6.57 & .410 & .683 \\
\hline & $\mathrm{N}$ & $\%$ & $\mathrm{~N}$ & $\%$ & $\chi^{2}$ & $\mathrm{p}$ \\
\hline Estado Civil & & & & & .225 & .636 \\
\hline Solteiro & 63 & 96.9 & 39 & 95.1 & & \\
\hline Casado & 2 & 3.1 & 2 & 4.9 & & \\
\hline Escalão Competitivo & & & & & 24.980 & .000 \\
\hline Juvenil/Júnior & 48 & 73.8 & 10 & 24.4 & & \\
\hline Sénior & 15 & 23.1 & 26 & 63.4 & & \\
\hline Master & 2 & 3.1 & 5 & 12.2 & & \\
\hline
\end{tabular}

\subsection{Procedimentos}

Os participantes desta investigação preencheram uma bateria de instrumentos de auto-resposta, tendo previamente recebido informação oral e escrita acerca da natureza e objectivos do estudo, da estrita confidencialidade das respostas e da importância do preenchimento de todos os itens. No caso dos participantes com idades inferiores a 18 anos, obteve-se o preenchimento de uma folha de consentimento informado por parte dos respectivos encarregados de educação.

A bateria de questionários foi respondida pelos nadadores em três momentos distintos: (i) aproximadamente uma semana antes de uma prova de competição com moderado e/ou elevado nível de dificuldade e importância; (ii) no dia da competição, após a realização desta; e (iii) cerca de uma a duas semanas depois da realização da competição desportiva. 


\subsection{Instrumentos}

Escalas de Ansiedade, Depressão e Stress - EADS-21 (DASS - Depression Anxiety Stress Scales; Lovibond e Lovibond, 1995; tradução e adaptação para a população portuguesa de Pais-Ribeiro, Honrado, \& Leal, 2004). Esta medida é constituída por 21 itens, distribuídos equitativamente por três dimensões, que pretendem avaliar respectivamente os estados afectivos de depressão, ansiedade e stress. Os sujeitos, tendo em conta a sua experiência na "semana passada", respondem a cada afirmação de acordo com uma escala tipo Likert com 4 pontos de gravidade ou frequência: "não se aplicou nada a mim", " aplicou-se a mim algumas vezes", "aplicou-se a mim muitas vezes", "aplicou-se a mim a maior parte das vezes". As pontuações mais elevadas em cada escala correspondem a estados afectivos mais negativos. A versão portuguesa da escala tem propriedades idênticas à versão original. Os valores de alpha de Cronbach encontrados por Ribeiro, Honrado e Leal (2004) foram .85 (.93 na versão de 14 itens) para a Depressão, .74 (.83 na versão de 14 itens) para a Ansiedade e .81 (.88 na versão de 14 itens) para o Stress. No presente estudo, os valores de consistência interna das subescalas Depressão, Ansiedade e Stress foram $\alpha=.804, \alpha=.473$ e $\alpha=.758$, respectivamente. Assim, no nosso estudo, serão utilizadas apenas as subescalas Depressão e Stress, cujas características psicométricas se revelaram adequadas4.

Questionário de Aceitação e Acção II (AAQ II - Acceptance and Action Questionnaire; Bond, et al., 2007; tradução e adaptação: Pinto Gouveia, Gregório, Dinis, \& Xavier, 2011). O AAQ-II pretende avaliar a inflexibilidade psicológica. Esta escala inclui 10 itens, respondidos, cada um deles, numa escala de 7 pontos ( $1=$ nunca verdadeiro; 7 = sempre verdadeiro). No presente estudo, o valor de consistência interna obtido foi $\alpha=.820$.

Escala das Formas de Auto-Criticismo e de Auto-Tranquilização (FSCRS - Forms of self-criticizing/attacking and self-reassuring scale; Gilbert, Clarke, Hempel, Miles, \& Irons, 2004; tradução e adaptação: Castilho, \& Pinto Gouveia, 2005). Esta escala pretende avaliar em que medida o indivíduo se auto-critica/ataca ou, pelo contrário, se reconforta/tranquiliza, "quando as coisas Ihe correm mal". A versão original é constituída por 22 itens, com uma escala de resposta de Likert de 5 pontos, onde o corresponde a "não sou assim" e 4 corresponde a "sou extremamente assim". Não há itens invertidos. Esta medida é composta por três factores: (1) o Eu Inadequado, que avalia a sensação de inadequação do Eu perante fracassos e recuos; (2) o Eu Detestado, que mede um sentimento de auto-repugnância/ódio e uma resposta destrutiva perante fracassos, caracterizada por uma perseguição

4 Foi utilizada a convenção de Pestana e Gageiro (2008), para qualificar a consistência interna da escala, precisamente, alphas de Cronbach inferiores a .60, é considerada uma consistência inaceitável; fraca entre .60 e .70; razoável entre .70 e .80 ; boa entre .80 e .90; e muito boa superior a .90 . 
agressiva com o intuito de se magoar a si próprio; e (3) o Eu Tranquilizador, que avalia a capacidade do Eu para se tranquilizar, reconfortar e acalmar perante experiências de fracasso.

$\mathrm{Na}$ escala original foram encontrados os seguintes valores para o alpha de Cronbach: .9o para a forma Eu Inadequado e .86 para as formas Eu Detestado e Eu Tranquilizador. No presente estudo, os valores de consistência interna obtidos foram: para os factores Eu Inadequado .829, para o Eu Detestado .670 e para o Eu Tranquilizador .840 .

Inventário de Competências Psicológicas para o Desporto - ICPD (PSIS - Form R-5; Mahoney, 1987; tradução e adaptação: Viana et al., 1993; Cruz \& Viana, 1993; Viana \& Cruz, 1993). Este instrumento trata-se da versão traduzida e adaptada do "Psychological Skills Inventory for Sports - PSIS (Form R-5)" (Mahoney, 1987). O ICPD contempla um total de 63 itens, sendo que os primeiros 45 itens correspondem à versão original, traduzida e adaptada, e os restantes itens (18 itens) foram retirados da primeira versão original do PSIS (não estando incluídos na versão mais recente do PSIS - Form R-5), para efeitos de adaptação em língua portuguesa. As respostas são dadas de acordo com uma escala do tipo Likert, de 5 pontos, de "Discordo completamente" a "Concordo completamente". Os itens do ICPD envolvem afirmações relacionadas com vários aspectos e factores psicológicos associados ao rendimento desportivo e estão distribuídos por seis escalas que se destinam a avaliar dimensões importantes para o rendimento desportivo: a) Controle da Ansiedade; b) Concentração; c) Auto-confiança; d) Preparação mental; e) Motivação; f) Espírito de equipa. Os resultados mais elevados traduzem maiores níveis de competência psicológica nas diferentes dimensões avaliadas.

Os estudos preliminares de validação da versão portuguesa e particularmente as análises de consistência interna das diferentes subescalas do ICPD (Viana et al., 1993; Cruz \& Viana, 1993; Viana e Cruz, 1993 cited in Cruz, 1996) sugeriram problemas na escala de Preparação Mental original, aspecto este comprovado também num estudo sobre a estrutura e validade factorial do PSIS (Chartrand et al., 1992 cited in Cruz, 1996). O mesmo se verificou com a escala de Espírito de Equipa, cuja consideração se mostra também algo problemática num estudo que contempla uma modalidade individual. No nosso estudo, os valores de consistência interna encontrados foram os seguintes: para o componente Controle de Ansiedade $\alpha=.606$, para o componente Concentração $\alpha=.577$, para o componente Auto-Confiança $\alpha=.852$, para o componente Preparação Mental $\alpha=-.476$, para o componente Motivação $\alpha=.638$ e para o componente Espírito de Equipa $\alpha=.198$. Assim, para efeitos do presente estudo, recorreu-se apenas à utilização das escalas Controle de Ansiedade (10 itens), Auto-Confiança (9 itens), Motivação (7 
itens) e Concentração (6 itens), cujas características psicométricas se revelaram mais adequadas.

Escala de Ansiedade no Desporto - EAD (SAS - Sport Anxiety Scale; Smith, Smoll \& Schultz, 1990; tradução e adaptação: Cruz \& Viana, 1997). Trata-se de um instrumento de avaliação multidimensional do traço de ansiedade competitiva, tendo sido construído para medir diferenças individuais no traço da Ansiedade Somática e em duas dimensões do traço de Ansiedade Cognitiva: Preocupação e Perturbação da Concentração. A SAS é composta por um total de 21 itens, reflectindo possiveis respostas à situação competitiva e apresentando 3 subescalas: a) Ansiedade Somática (9 itens); b) Preocupação (7 itens); e c) Perturbação da Concentração (5 itens). Para cada item os sujeitos respondem, como reagem geralmente, antes ou durante a competição, de acordo com uma escala de 4 pontos ( 1 = Nada; 4 = Muito). Os resultados de cada subescala são obtidos somando os valores de cada um dos respectivos itens. Paralelamente, pode obter-se também um resultado total do traço de ansiedade competitiva, adicionando os resultados totais das 3 subescalas.

Os estudos anteriores de adaptação e validação da versão portuguesa da SAS não só confirmaram a sua estrutura factorial, como reflectiram, de um modo geral, características psicométricas muito aceitáveis, evidentes nos coeficientes alpha de Cronbach obtidos em cada subescala: .84, .65 e .91, respectivamente para as subescalas de Preocupação, Perturbação da Concentração e Ansiedade Somática (Cruz \& Viana, 1993 cited in Cruz, 1996). No presente estudo, os valores de consistência interna obtidos foram $\alpha=.869$ para a Preocupação, $\alpha=.618$ para a Perturbação da Concentração e $\alpha=.848$ para a Ansiedade Somática.

Escala de Avaliação Cognitiva da Competição - Percepção de Ameaça (EACC-PA; Cruz, 1994, 1996). Trata-se de uma escala desenvolvida por Cruz $(1994,1996)$ que visa avaliar o estilo geral de avaliação cognitiva primária, isto é, as interpretações primárias acerca de "o que está em jogo" na competição desportiva, na perspectiva de cada atleta, e que os leva a experienciarem stress e ansiedade na situação de competição. A EACC-PA é uma adaptação de instrumentos similares desenvolvidos e aplicados por Lazarus e colaboradores noutros contextos (Lazarus \& Folkman, 1984 cited in Cruz, 1996). Esta escala é composta por 8 itens e, para cada item, os respondentes indicam até que ponto é que cada afirmação se aplica ao seu caso, numa escala tipo Likert de 5 pontos ( 1 = não se aplica; 5 = aplica-se muito). Os resultados mais elevados reflectem a tendência para percepcionar a competição desportiva como mais ameaçadora ou para percepcionar niveis mais elevados de ameaça ao Eu, à auto-estima e ao bem-estar pessoal, gerados pela competição.

Em face da inexistência de estudos anteriores de validação e adaptação da EACCPA, pode-se enumerar um estudo realizado por Cruz (1996), onde o autor analisou 
mais cuidada e detalhadamente as características psicométricas desta escala, tendo encontrado uma elevada consistência interna, evidenciada pelo alpha de Cronbach de .87. No presente estudo, através da análise da consistência interna, obteve-se um alpha de Cronbach de .850 .

Grelha Motivacional para o Atleta (GMA; Pinto Gouveia, \& Xavier, 2009). Este instrumento foi construído para o presente estudo, tendo em conta os objectivos propostos. Assim, trata-se de um questionário destinado a avaliar a motivação do atleta da modalidade de natação pura para os treinos e para a competição desportiva. Esta grelha contém 12 itens, sendo que, para cada item, é apresentada uma frase incompleta face à qual o atleta terá de avaliar a sua motivação, de acordo com uma escala que varia entre 1 ("nada motivado(a)") e 7 ("extremamente motivado(a)"). Os resultados mais elevados reflectem níveis motivacionais mais altos para os treinos e para a competição desportiva. A consistência interna obtida foi de $\alpha=.875$.

Grelha de Percepção de Desempenho para o Atleta (GPDA; Pinto Gouveia, \& Xavier, 2009). Este questionário, também construído para o presente estudo, destina-se a avaliar a percepção de cada atleta acerca do seu desempenho após a realização da prova de competição de natação. Este instrumento engloba um total de 9 itens, sendo que, para cada item, é apresentada uma frase incompleta face à qual se deve assinalar, numa escala de tipo Likert de 7 pontos (1 corresponde a "péssimo"; 7 corresponde a "excelente"), o número que melhor corresponde ao grau de percepção de desempenho de cada atleta. Os resultados mais elevados traduzem um desempenho percebido pelo atleta como alto, após a realização da competição desportiva. Neste estudo, a consistência interna revelou um alpha de Cronbach .957.

\section{Resultados}

\section{MOMENTO I}

Estudo da relação entre a Aceitação, o Auto-Criticismo, as Competências Psicológicas para o Desporto, a Ansiedade Competitiva e a Percepção de Ameaça na Competição (Momento 1)

Começámos por analisar a relação entre as variáveis em estudo na fase anterior à prova de competição (uma semana antes), procedendo à análise das correlações de Pearson 5 (cf. Quadro 2).

5 Segundo Pestana e Gageiro (2008), uma correlação menor que .2 indica uma associação linear muito baixa; entre .2 e .39 baixa; entre .4 e .69 moderada; entre .7 e .89 alta; e entre .9 e 1 uma associação muito alta. 
Quadro 2. Correlações entre as variáveis em estudo no Momento 1 ( $N=106)$

\begin{tabular}{l|c|c|c|c}
\hline \multirow{2}{*}{ Variáveis } & \multicolumn{3}{|c}{ EAD } \\
\cline { 2 - 5 } & $\begin{array}{c}\text { Ansiedade } \\
\text { Somática }\end{array}$ & Preocupação & $\begin{array}{c}\text { Perturbação da } \\
\text { Concentração }\end{array}$ & $\begin{array}{c}\text { Ansiedade } \\
\text { Competitiva } \\
\text { Total }\end{array}$ \\
\hline AAQ II & $-.282^{* *}$ & $-.567^{* *}$ & $-.262^{* *}$ & $-.450^{* *}$ \\
FSCRS & & & & $.248^{*}$ \\
Eu inadequado & $.297^{* *}$ & $.532^{* *}$ & $.289^{* *}$ & $.438^{* *}$ \\
Eu detestado & $.283^{* *}$ & $.337^{* *}$ & $-.356^{* *}$ \\
Eu tranquilizador & $-.222^{*}$ & $-.334^{* *}$ & $-.203^{*}$ & $-.305^{* *}$ \\
ICPD & $-.467^{* *}$ & $-.544^{* *}$ & $-.355^{* *}$ & $-.556^{* *}$ \\
Controle da Ansiedade & $-.359^{* *}$ & $-.498^{* *}$ & $-.519^{* *}$ & $-.524^{* *}$ \\
Concentração & $-.393^{* *}$ & $-.666^{* *}$ & $-.365^{* *}$ & $-.573^{* *}$ \\
Auto-Confiança & -.023 & -.130 & $-.193^{*}$ & -.116 \\
Motivação & $.432^{* *}$ & $.728^{* *}$ & $.485^{* *}$ & $.650^{* *}$ \\
\hline EACC-PA & & & & \\
\hline
\end{tabular}

${ }^{* *} \mathrm{p} \leq .01 ;{ }^{*} \mathrm{p} \leq .05$

Os resultados, apresentados no Quadro 2, demonstram que existem correlações negativas entre todas as dimensões do traço de Ansiedade Competitiva (em particular, as suas vertentes de ansiedade somática, ansiedade cognitiva e a subescala ansiedade competitiva total) e a Aceitação, apresentando magnitudes a variar entre baixas (Ansiedade Somática $(r=-.282 ; p \leq .01)$ e a Perturbação da Concentração $(r=-.262 ; p \leq .01)$ a moderadas (Preocupação $r=-.567 ; p \leq .01$ ) e a Ansiedade Competitiva Total ( $r=-.450 ; p \leq .01)$. Similarmente, verificam-se associações negativas de magnitude baixa entre as dimensões do traço de Ansiedade Competitiva e o Eu tranquilizador.

O traço de Ansiedade Competitiva apresenta correlações negativas de magnitudes que variam entre muito baixa, baixa e moderada, com as Competências Psicológicas para o Desporto (em particular com as competências Controle da Ansiedade, Concentração e Auto-Confiança). A vertente Perturbação da Concentração correlaciona-se negativamente, de magnitude muito baixa, com a competência psicológica Motivação ( $r=-.193 ; p \leq .05)$.

Por outro lado, o traço de Ansiedade Competitiva correlaciona-se positivamente com o Auto-Criticismo, com magnitudes que variam entre baixas e moderadas. Existem ainda associações positivas de magnitudes moderadas e altas entre todas as dimensões do traço de Ansiedade Competitiva e a Percepção de Ameaça gerada pela competição desportiva. 


\section{Preditores da Ansiedade Competitiva (Momento 1)}

A partir dos resultados obtidos no estudo anterior e no sentido de identificarmos quais as variáveis preditoras significativas da Ansiedade Competitiva (avaliada pela EAD), no momento anterior à prova de competição, procedemos à realização de uma análise de regressão, em que introduzimos como variáveis independentes a subescala de Motivação das Competências Psicológicas para o Desporto (avaliada pelo ICPD), as formas de Auto-Criticismo (avaliadas pela FSCRS) e a Aceitação (avaliada pelo AAQ-II), no momento pré-competitivo, e como variável dependente ou critério a Ansiedade Competitiva (avaliada pela EAD). Este estudo reporta-se ao momento pré-competitivo (uma semana antes da prova de competição) (cf. Quadro 3).

Quadro 3. Análise de Regressão com a Ansiedade Competitiva como variável critério

\begin{tabular}{lccccc}
\hline Modelo & $\mathrm{R}$ & $\mathrm{R}^{2}$ & $\mathrm{~F}$ & $\mathrm{gl}$ & $\mathrm{P}$ \\
\hline 1 & .516 & .266 & 7.264 & $(5,100)$ & .000 \\
\hline & & & & & \\
\hline Modelo & Preditores & & $\beta$ & $\mathrm{t}$ & $\mathrm{P}$ \\
\hline 1 & Aceitação & & -.257 & -2.295 & .024 \\
\hline
\end{tabular}

A partir dos dados representados no Quadro 3, verifica-se que o modelo reveste-se de significância estatística, explicando $26.6 \%$ da variância da Ansiedade Competitiva $\left[F_{(5,100)}=7.264 ; p=.000\right]$, onde a Aceitação se assume como o único preditor significativo com um $\beta=-.257$ ( $t=-2.295 ; p=.024)$.

\section{Preditores da Percepção de Ameaça na Competição (Momento 1)}

A partir dos resultados obtidos no estudo de correlações e no sentido de identificarmos quais as variáveis que predizem de forma significativa a Percepção de Ameaça na Competição, realizámos uma análise de regressão, em que introduzimos como variáveis independentes a subescala de Motivação das Competências Psicológicas para o Desporto (avaliada pelo ICPD) no momento pré-competitivo; as formas de Auto-Criticismo (avaliadas pela FSCRS) no momento pré-competitivo; e a Aceitação (avaliada pelo AAQ-II) no momento pré-competitivo; e como variável dependente ou critério a Percepção de Ameaça na Competição (avaliada pela EACC-PA). Este estudo reporta-se ao momento pré-competitivo (uma semana antes da prova de competição) (cf. Quadro 4). 
Quadro 4. Análise de Regressão com a Percepção de Ameaça na Competição como variável critério

\begin{tabular}{lccccc}
\hline Modelo & $\mathrm{R}$ & $\mathrm{R}^{2}$ & $\mathrm{~F}$ & $\mathrm{gl}$ & $\mathrm{P}$ \\
\hline 1 & .588 & .346 & 10.576 & $(5,100)$ & .000 \\
\hline
\end{tabular}

\begin{tabular}{lcccc}
\hline Modelo & Preditores & $\beta$ & $\mathrm{t}$ & $\mathrm{p}$ \\
\hline 1 & Aceitação & -.241 & -2.283 & .025 \\
& Eu inadequado & .494 & 4.271 & .000 \\
\hline
\end{tabular}

A partir dos dados representados no Quadro 4, constata-se que o modelo é estatisticamente significativo, explicando $34.6 \%$ da variância da Percepção de Ameaça gerada pela competição desportiva $\left[F_{(5,100)}=10.576 ; p=.000\right]$. Assim, observamos que surgem como preditores significativos, de um maior para um menor contributo, a forma Eu inadequado do Auto-Criticismo com um $\beta=.494(t=4.271 ; p=.000)$ e a Aceitação com um $\beta=-.241$ ( $t=-4.271 ; p=.000)$.

\section{MOMENTO II}

Estudo da Motivação para treinar após a Percepção de Desempenho na prova de competição

Começámos por analisar a relação entre as variáveis em estudo (cf. Quadro 5). Os dados obtidos neste estudo referem-se aos momentos de antecipação (Momento 1) e de avaliação imediatamente após a competição desportiva (Momento 2).

Quadro 5. Correlações entre as variáveis em estudo nos momentos 1 e $2(\mathrm{~N}=106)$

\begin{tabular}{l|c|c}
\hline \multirow{2}{*}{ Variáveis } & $\begin{array}{c}\text { Grelha Motivacional } \\
\text { do Atleta (Momento 2) }\end{array}$ & $\begin{array}{c}\text { Grelha de Percepção } \\
\text { de } \begin{array}{c}\text { Desempenho para o } \\
\text { Atleta (Momento2) }\end{array}\end{array}$ \\
\cline { 2 - 3 } ICPD & .123 & .130 \\
Controlo Ansiedade (Momento 1) & .173 & .163 \\
Concentração (Momento 1) & $.218^{*}$ & $.288^{* *}$ \\
Auto-Confiança (Momento 1) & $.275^{* *}$ & $.274^{* *}$ \\
Motivação (Momento 1) & $.48^{* *}$ & .180 \\
EAD & & -.133 \\
Ansiedade Somática (Momento 1) & -.141 & -.150 \\
$\begin{array}{l}\text { Preocupação (Momento 1) } \\
\text { Perturbação da Concentração }\end{array}$ & -.112 & -.146 \\
(Momento 1) & & -.168 \\
$\begin{array}{l}\text { Ansiedade Competitiva Total } \\
\text { (Momento 1) }\end{array}$ & $-.211^{*}$ & -.182 \\
EACC-PA (Momento 1) \\
$\begin{array}{l}\text { Grelha Motivacional do Atleta (Mo- } \\
\text { mento 1) }\end{array}$
\end{tabular}




\begin{tabular}{l|c|c} 
FSCRS & & \\
Eu inadequado (Momento 2) & -.181 & $-.278^{* *}$ \\
Eu detestado (Momento 2) & $-.225^{*}$ & -.094 \\
$\quad$ Eu tranquilizador (Momento 2) & $.215^{*}$ & $.224^{*}$ \\
$\begin{array}{l}\text { Grelha de Percepção de Desempenho } \\
\text { para o Atleta (Momento 2) }\end{array}$ & $.481^{* *}$ & - \\
\hline
\end{tabular}

A partir da análise das correlações descritas no Quadro 5, verifica-se que a Motivação do Atleta Após a Competição Desportiva para treinar/competir (avaliada pela Grelha Motivacional do Atleta) apresenta correlações positivas de magnitudes moderadas com a Motivação Antes da Competição Desportiva ( $r=.649 ; p \leq .01)$ para treinar/competir (avaliada pela GMA), assim como com a Percepção de Desempenho na situação competitiva $(r=.481 ; p \leq .01)$. A Motivação do Atleta Após a Competição Desportiva para treinar/competir (avaliada pela GMA) evidencia igualmente correlações positivas com magnitudes que variam entre moderada e baixa com as Competências Psicológicas para o Desporto, em particular com a subescala Motivação ( $r=.458 ; p \leq .01)$, a subescala Auto-Confiança $(r=.278 ; p \leq .01)$ e a subescala Concentração ( $r=.218 ; p \leq .05)$. Destaca-se uma correlação positiva de magnitude baixa entre a Motivação do Atleta Após a Competição Desportiva para treinar/competir (avaliada pela GMA) e a forma Eu tranquilizador ( $r=.215 ; p \leq .05$ ) no momento após a competição. Por outro lado, constata-se que a Motivação do Atleta Após a Competição Desportiva para treinar/competir (avaliada pela GMA) apresenta correlações negativas de magnitude baixa com a forma Eu detestado $(r=-.225 ; p \leq .05)$, assim como com a sintomatologia ansiosa, em particular com a Perturbação da Concentração ( $r=-.211 ; p \leq .05)$.

Em relação à Percepção de Desempenho do Atleta na Competição (avaliada pela Grelha de Percepção de Desempenho para o Atleta no Momento 2), esta apresenta correlações positivas baixas com a Motivação do Atleta Antes da Competição Desportiva para treinar/competir ( $r=.239 ; p \leq .05)$; com as Competências Psicológicas para o Desporto, em particular a subescala Concentração $(r=.288 ; p \leq .01)$ e a subescala Auto-Confiança ( $r=.274 ; p \leq .01)$; assim como, com a forma Eu tranquilizador ( $r=.224 ; p \leq .05)$. Verifica-se ainda uma correlação negativa moderada entre a Percepção de Desempenho do Atleta na Competição (avaliada pela GPDA no Momento 2 ) e a forma Eu inadequado ( $r=-.278 ; p \leq .01)$ no momento após a competição (Momento 2).

\section{Preditores da Motivação do Atleta para treinar/competir}

No sentido de compreendermos quais os melhores preditores, entre as variáveis específicas do contexto desportivo, da Motivação do Atleta Após a Competição Desportiva para treinar/competir (avaliada pela Grelha Motivacional do Atleta), 
realizámos uma análise de regressão múltipla hierárquica ou por blocos, em que introduzimos no primeiro bloco a subescala Perturbação da Concentração (avaliada pela $\mathrm{EAD}$ ) no momento pré-competitivo; no segundo bloco acrescentámos as competências psicológicas Concentração, Auto-Confiança e Motivação (avaliadas pelo ICPD) no momento pré-competitivo; no terceiro bloco, a Percepção de Desempenho do Atleta na situação competitiva (medida pela GPDA); e, finalmente, no quarto bloco acrescentámos a Motivação do Atleta Antes da Competição Desportiva (avaliada pela Grelha Motivacional para o Atleta) (cf. Quadro 6).

Quadro 6. Análise de Regressão Múltipla Hierárquica ou por Blocos com a Motivação do Atleta (Momento 2) como variável critério

\begin{tabular}{l|c|c|c|c|c}
\hline Modelo & $\mathrm{R}$ & $\mathrm{R}^{2}$ & $\mathrm{~F}$ & $\mathrm{gl}$ & $\mathrm{p}$ \\
\hline 1 & .211 & .045 & 4.848 & $(1,104)$ & .030 \\
2 & .480 & .230 & 8.134 & $(3,101)$ & .000 \\
3 & .617 & .381 & 24.380 & $(1,100)$ & .000 \\
4 & .736 & .542 & 34.846 & $(1,99)$ & .000 \\
\hline
\end{tabular}

\begin{tabular}{llccc}
\hline Modelo & Preditores & $\beta$ & $\mathrm{t}$ & $\mathrm{p}$ \\
\hline 1 & EAD Perturbação da Concentração (Momento1) & -.211 & -2.202 & .030 \\
2 & ICPD Motivação (Momento1) & .411 & 4.295 & .000 \\
\multirow{2}{*}{3} & ICPD Motivação (Momento1) & .375 & 4.335 & .000 \\
& Percepção de Desempenho (Momento2) & .410 & 4.938 & .000 \\
\multirow{2}{*}{4} & Percepção de Desempenho (Momento2) & .356 & 4.921 & .000 \\
& Motivação do Atleta (GMA; Momento1) & .547 & 5.903 & .000 \\
\hline
\end{tabular}

A partir dos dados apresentados no Quadro 6, verifica-se que o modelo 1 se reveste de significância estatística, explicando $4.5 \%$ da variância na Motivação do Atleta Após a Competição Desportiva $\left(F_{(1,104)}=4.848 ; p=.030\right)$. Assim, observase que a Perturbação da Concentração antes da prova de competição apresenta um valor preditivo, sendo o seu efeito de $\beta=-.211(t=-2.202 ; p=.030)$. O modelo 2 é estatisticamente significativo e explica $23 \%$ da variância da Motivação do Atleta Após a Competição Desportiva $\left(F_{(3,101)}=8.134 ; p=.000\right)$. Porém, a Perturbação da Concentração antes da situação competitiva deixa de ter poder preditivo quando fazemos entrar no modelo as Competências Psicológicas, passando a ser a competência psicológica Motivação, antes da competição, a melhor variável preditora $(\beta=.411 ; t=4.295 ; p=.000)$ da Motivação do Atleta Após a Competição Desportiva. O modelo 3 também é estatisticamente significativo, explicando 38.1\% da variação na Motivação do Atleta Após a Competição Desportiva $\left(F_{(1,100)}=24.380\right.$; $p=.000$ ), onde surge a Percepção de Desempenho na situação competitiva como melhor preditora da Motivação do Atleta depois da prova de competição, com um contributo maior ( $\beta=.410 ; t=4.938 ; p=.000$ ) comparativamente à competência psicológica Motivação antes da competição ( $\beta=.375 ; t=4.335 ; p=.000)$. O último modelo reveste-se de significância estatística e explica $54.2 \%$ da variância da 
Motivação do Atleta Após a Competição Desportiva $\left(F_{(1,99)}=34.846 ; p=.000\right)$, onde a competência psicológica Motivação deixa de ser significativa quando entra no modelo a Motivação do Atleta Antes da Situação Competitiva. Assim, neste último modelo, surgem como melhores preditores da Motivação do Atleta Após a Competição Desportiva, por ordem de importância, a Motivação do Atleta Antes da Situação Competitiva ( $\beta=.547 ; t=5.903 ; p=.000)$ e a Percepção de Desempenho na situação de competição $(\beta=.356 ; t=4.921 ; p=.000)$.

\section{MOMENTO III}

\section{A influência da Aceitação na Sintomatologia Ansiosa e Depressiva do Atleta}

Começámos por analisar as correlações entre as variáveis em estudo nos diferentes momentos de antecipação da competição, de preparação para a competição (Momento 1), durante a competição (Momento 2) e numa fase de reacção posterior à competição (Momento 3) (cf. Quadro 7).

Quadro 7. Correlações entre a Aceitação (Momento 1), a Percepção de Desempenho (Momento 2) e a Sintomatologia Ansiosa e Depressiva (Momentos 1, 2 e 3) ( $N=106)$

\begin{tabular}{lcccccc}
\hline & \multicolumn{5}{c}{ EADS-21 } \\
\cline { 2 - 6 } Variáveis & $\begin{array}{c}\text { Stress (Mo- } \\
\text { mento 1) }\end{array}$ & $\begin{array}{c}\text { Stress (Mo- } \\
\text { mento 2) }\end{array}$ & $\begin{array}{c}\text { Stress (Mo- } \\
\text { mento 3) }\end{array}$ & $\begin{array}{c}\text { Depressão } \\
\text { (Momento 1) }\end{array}$ & $\begin{array}{c}\text { Depressão } \\
\text { (Momento 2) }\end{array}$ & $\begin{array}{c}\text { Depressão } \\
\text { (Momento 3) }\end{array}$ \\
\hline $\begin{array}{l}\text { Aceitação } \\
\text { (Momento 1) }\end{array}$ & $-.443^{* *}$ & $-.219^{*}$ & -.154 & $-.582^{* *}$ & $-.304^{* *}$ & $-.345^{* *}$ \\
$\begin{array}{l}\text { Percepção de } \\
\begin{array}{l}\text { Desempenho } \\
\text { (Momento 2) }\end{array}\end{array}$ & -.020 & $-.211^{*}$ & -.098 & -.097 & $-.355^{* *}$ & -.172 \\
\hline
\end{tabular}

${ }^{* *} \mathrm{p} \leq .01 ;{ }^{*} \mathrm{p} \leq .05$

A partir da análise das correlações (cf. Quadro 7), verifica-se que, no momento de antecipação da competição (Momento 1), existem correlações negativas moderadas quer entre o estado afectivo Depressão e a Aceitação ( $r=-.582 ; p \leq .01)$; quer entre a dimensão Stress e a Aceitação ( $r=-.443 ; p \leq .01)$. Na fase após a competição desportiva (Momento 2), existem associações negativas de magnitudes baixa entre a dimensão Depressão e a Aceitação ( $r=-.304$; $p \leq .01$ ); assim como, entre a dimensão Stress e a Aceitação ( $r=-.219 ; p \leq .05)$. Na fase de reacção posterior à competição (Momento 3 ), verifica-se uma associação negativa baixa entre a dimensão Depressão e a Aceitação ( $r=-.345 ; p \leq .01)$.

Existem ainda correlações negativas de magnitude baixa entre a dimensão Depressão e a Percepção de Desempenho na competição ( $r=-.355 ; p \leq .01$ ); bem como, entre a dimensão Stress e a Percepção de Desempenho na competição ( $r=-.211 ; p \leq .05)$, após a competição (Momento 2$)$. 


\section{Preditores da Depressão na fase de reacção posterior à situação de competição (Momento 3)}

A partir dos resultados obtidos no estudo de correlações e no sentido de compreendermos quais os melhores preditores da dimensão Depressão (avaliada pela EADS-21) na fase de reacção posterior à competição (Momento 3), realizámos uma análise de regressão múltipla hierárquica ou por blocos, em que introduzimos como variáveis independentes a Aceitação no momento pré-competitivo (avaliada pelo AAQ-II); e o Desempenho percepcionado pelo atleta a seguir à realização da prova de competição (medido pela Grelha de Percepção de Desempenho para o Atleta); e como variável critério ou dependente a dimensão Depressão (avaliada pela EADS-21) na fase de reacção posterior à competição (cf. Quadro 8).

Quadro 8. Análise de Regressão Múltipla Hierárquica ou por Blocos com a Depressão (Momento 3) como variável critério

\begin{tabular}{lccccc}
\hline Modelo & $\mathrm{R}$ & $\mathrm{R}^{2}$ & $\mathrm{~F}$ & $\mathrm{gl}$ & $\mathrm{P}$ \\
\hline 1 & .345 & .119 & 14.019 & $(1,104)$ & .000 \\
2 & .368 & .135 & 1.968 & $(3,103)$ & .164 \\
\hline
\end{tabular}

\begin{tabular}{lcccc}
\hline Modelo & Preditores & $\beta$ & $t$ & $p$ \\
\hline 1 & Aceitação (Momento1) & -.345 & -3.744 & .000 \\
\hline
\end{tabular}

A partir dos dados apresentados no Quadro 8, observa-se que o modelo 1 é estatisticamente significativo $\left(F_{(1,104)}=14.019 ; p=.000\right)$, sendo que $11.9 \%$ da variação na sintomatologia depressiva na fase de reacção posterior à prova de competição é explicada pela Aceitação no momento pré-competitivo, cuja contribuição é significativa $(\beta=-.345 ; t=-3.744 ; p=.000)$.

\section{Discussão}

A Aceitação das experiências internas e o abandono consciente de comportamentos que funcionam como evitamento experiencial, permitem potenciar a flexibilidade psicológica e o bem-estar. Em contrapartida, o Auto-criticismo, uma forma de relação interna ( $E$ u com o Eu) de dominância-subordinação, encontra-se subjacente a muitas formas de dificuldades psicológicas (Gilbert \& Irons, 2005). De facto, um grande número de investigações no âmbito da psicopatologia tem reconhecido a existência de problemas associados ao auto-criticismo, assim como as dificuldades existentes em ajudar estes indivíduos a desenvolver uma atitude de aceitação e de auto-tranquilização dirigidos ao Eu.

Dada a importância que estes constructos têm vindo a assumir no domínio da Psicologia e a potencial implicação dos mesmos no contexto desportivo, o estudo 
aqui apresentado pretendeu avaliar, numa população de atletas de natação, em que medida o traço auto-criticismo, bem como o processo de aceitação psicológica influenciam a motivação dos atletas para os treinos e a sintomatologia depressiva e ansiosa experienciada pelos mesmos, quando percepcionam um desempenho fraco na competição desportiva.

Os resultados encontrados no estudo de correlações das variáveis em estudo no momento de antecipação e preparação para a competição (Momento 1), apoiam a nossa hipótese ao revelar que os atletas com um traço mais elevado de ansiedade competitiva apresentam níveis mais baixos de uma atitude de aceitação das suas experiências privadas avaliadas como indesejáveis, de auto-tranquilização dirigida ao Eu, bem como menores níveis de competências psicológicas funcionais para o desporto. Por outro lado, os atletas com um traço mais elevado de ansiedade competitiva revelam níveis mais elevados de auto-criticismo e avaliam a situação competitiva como mais ameaçadora.

Estes resultados corroboram a nossa hipótese e estão de acordo com os resultados encontrados na literatura, que embora não tenha investigado estas relações em particular, revela que a relutância em permanecer em contacto com acontecimentos privados avaliados negativamente e a tentativa crónica para alterar a forma como esses acontecimentos ou circunstâncias surgem (experiências emocionais e psicológicas privadas, contendo intensidade, frequência e valência negativa), são fortes factores que contribuem para a psicopatologia (Kashdan et al., 2006). Particularmente, na relação entre o evitamento experiencial (o oposto da aceitação psicológica) e a sintomatologia ansiosa, estudos (Feldner, Zvolensky, Eifert, \& Spira, 2003; Karekla, Forsyth, \& Kelly, 2004; Spira, Zvolensky, Eifert, \& Feldner, 2004; Kashdan et al., 2006) demonstram que o evitamento experiencial amplifica a sintomatologia ansiosa em indivíduos sem história de distúrbios de ansiedade. Um estudo realizado em Portugal (Costa \& Pinto Gouveia, 2010), com o objectivo de analisar o efeito mediador do evitamento experiencial na relação entre o coping e a psicopatologia em adultos com diagnóstico de dor crónica, evidenciou correlações expressivas positivas entre o evitamento experiencial e a depressão, a ansiedade e o stress. Os resultados (Costa \& Pinto Gouveia, 2010) mostram ainda que o evitamento experiencial tem um efeito mediador na relação entre o coping e a depressão e o stress, o que sugere que a psicopatologia não é necessariamente um produto directo do coping, havendo outros processos envolvidos, tal como o evitamento experiencial.

Além disso, os autores (John \& Gross, 2003; Kashdan et al., 2006) referem igualmente que o evitamento emocional crónico interfere com o prazer em estar completamente absorvido numa actividade, resultando numa menor frequência de acontecimentos positivos e diminuição de emoções positivas. 
Adicionalmente, os sentimentos e os pensamentos auto-críticos podem ser encarados como formas de perseguição e hostilização internas, sendo forte fonte de stress (Gilbert et al., 2004). Com efeito, segundo Gilbert e colaboradores (2006), as cognições e os sentimentos de auto-desvalorização, auto-condenação e autocriticismo ou auto-ataque estão associados a elevadas dificuldades na saúde mental.

O estudo dos preditores da ansiedade competitiva no momento pré-competitivo (Momento 1) mostra que a aceitação se revelou a melhor preditora da ansiedade competitiva avaliada pela Escala de Ansiedade no Desporto. Estes dados permitem concluir que é tanto maior a ansiedade competitiva experienciada pelos atletas, quanto mais se envolvem no processo de evitamento experiencial e menos adoptam uma atitude de aceitação das suas experiências internas. Estes resultados vão ao encontro de um estudo realizado por Kashdan e colaboradores (2006) que encontraram uma relação forte entre evitamento experiencial e patologia relacionada com a ansiedade.

Assim, os resultados do nosso estudo sugerem que uma intervenção directa ao nível da aceitação, no contexto desportivo, poderá ter um importante papel no bem-estar dos atletas, assim como no aperfeiçoamento da qualidade prática/treino, do desempenho competitivo e no aumento do prazer da experiência desportiva. Do mesmo modo, pode contribuir para que em futuras investigações se explore não só esta relação, mas também a utilidade da aplicação de técnicas de aceitação à população de atletas com a finalidade de aumentar o desempenho competitivo.

O estudo dos preditores da percepção de ameaça na competição (Momento 1) mostra que o auto-criticismo (em particular a forma Eu inadequado) revelou-se a melhor variável preditora, seguida da aceitação no momento pré-competitivo. Os resultados mostram que é tanto maior a percepção de ameaça gerada pela competição quanto mais os atletas apresentam um traço de auto-criticismo, especificamente na forma Eu inadequado, e menos adoptam uma atitude de aceitação das suas experiências internas.

Para melhor compreendermos estes resultados temos de ter em conta a análise do conteúdo conceptual do constructo de auto-criticismo, que relativamente às formas, pode focar-se nos erros e sentido de inadequação perante fracassos e derrotas. Nesta medida, a competição e os níveis de activação por ela gerados podem constituir uma situação ameaçadora e mesmo aversiva, podendo ser evitada pelos atletas de forma a não demonstrarem fracasso ou falta de capacidade (Araújo \& Gomes, 2005).

Os resultados encontrados no estudo de correlações das variáveis em estudo no momento da competição (Momento 2) mostram que os atletas que se encontram à partida motivados para treinar e competir (Momento 1), apresentam maiores 
níveis de competências psicológicas funcionais (em particular, motivação, autoconfiança e concentração), têm uma atitude de auto-tranquilização, experienciam menores sentimentos de agressão ao Eu, baixos níveis de cognições e pensamentos interferentes com a sua concentração e percepcionam o seu desempenho com bom/excelente na situação competitiva, encontram-se, após a realização da competição desportiva, mais motivados para treinar (Momento 2).

Em termos gerais, os resultados estão em congruência com os dados descritos na literatura, pois tal como mostra um estudo realizado em Portugal por Cruz (1996), que pretendeu analisar a importância, para o sucesso desportivo, da percepção de ameaça na competição, do traço de ansiedade competitiva e de várias competências psicológicas junto de atletas de alta competição, os atletas de elite nacional parecem caracterizar-se por um maior nivel de auto-confiança e motivação, assim como pela experiência de baixos níveis de ansiedade e de cognições e pensamentos interferentes com a sua concentração em situações competitivas.

Relativamente à percepção de desempenho do atleta na competição (Momento 2), os resultados demonstram que os atletas que se encontram previamente motivados para treinar e competir, apresentam maiores niveis de competências psicológicas funcionais para o desporto, e se focam menos nos erros e sentido de inadequação perante fracassos e derrotas, tendem a percepcionar o seu desempenho como bom/excelente após a situação competitiva.

O estudo dos preditores da motivação do atleta para treinar/competir, após a realização da prova de competição (Momento 2), mostra que a motivação do atleta no momento pré-competitivo revelou-se a melhor variável preditora, seguida da percepção de desempenho por parte do atleta após a realização da situação competitiva. Os resultados permitem-nos concluir, de acordo com o esperado, que é tanto maior a motivação dos atletas para treinar/competir após a competição desportiva, quanto mais motivados estiverem antes da competição desportiva e percepcionarem o seu desempenho como bom/excelente na situação competitiva. Estes dados sugerem que um atleta que se encontre à partida motivado para treinar e competir, que produza respostas relevantes facilitadoras do seu desempenho na situação competitiva, a sua prestação de sucesso contribui para manter ou aumentar, posteriormente, o seu grau motivacional.

Os resultados do estudo de correlações entre as variáveis em estudo no momento de reacção posterior à competição desportiva (Momento 3) mostram que os atletas que aceitam consciente e activamente a experiência dos pensamentos, sentimentos e sensações corporais tal como eles ocorrem, que permanecem em contacto com esses eventos internos e que abandonam conscientemente os comportamentos que funcionam como evitamento experiencial, apresentam baixos níveis de sintomatologia depressiva e ansiosa nos diferentes momentos de pré-competição 
(Momento 1) e após a competição (Momento 2), assim como baixos níveis de sintomatologia depressiva numa fase de reacção posterior à competição (Momento 3). Adicionalmente, e como seria de esperar, os atletas que percepcionam o seu desempenho como bom/excelente na situação competitiva, experienciam menores níveis de depressão e ansiedade após a competição (Momento 2).

Existe na literatura um conjunto de estudos significativos que, embora não aborde esta relação em particular, confirma a relação entre o evitamento experiencial e as medidas de psicopatologia: em amostras clínicas e não clínicas, o evitamento experiencial está fortemente correlacionado com medidas de psicopatologia geral (Hayes et al., 2004; Kashdan et al., 2006) e medidas específicas de ansiedade e depressão (Kashdan et al., 2006).

No estudo dos preditores da depressão na fase de reacção posterior à situação competitiva (Momento 3), destaca-se a Aceitação como melhor preditora. Os resultados mostram que é tanto maior a sintomatologia depressiva experienciada pelos atletas na fase de reacção posterior à situação competitiva quanto mais se envolvem no processo de evitamento experiencial e menos adoptam uma atitude de aceitação das suas experiências internas (por exemplo, pensamentos, sensações, emoções). Estes resultados mostram-se em consonância com a literatura, que demonstra empiricamente que a rigidificação do evitamento experiencial encontra-se associada aos indicadores de psicopatologia, tais como a depressão e a ansiedade (Kashdan et al., 2006).

Concluindo, importa salientar que por um lado, os resultados do presente estudo permitem comprovar a importância do constructo de aceitação no funcionamento adaptativo, assim como a pertinência de uma intervenção focada no desenvolvimento do mesmo como uma resposta contrária ao controlo emocional, ao evitamento experiencial e ao auto-criticismo, perante fracassos, em actividades consideradas importantes para os indivíduos. Por outro lado, os resultados do nosso estudo poderão contribuir igualmente para o desenvolvimento do conhecimento no domínio da Psicologia do Desporto.

\section{Limitações e Investigações Futuras}

Algumas limitações podem ser apontadas a este estudo. Para além das desvantagens inerentes ao uso de instrumentos de auto-resposta em geral, salienta-se a avaliação do desempenho dos atletas, que, contrariamente ao nosso objectivo inicial (que era obter uma medida objectiva de desempenho do atleta), acabou por ser uma medida global de avaliação subjectiva de desempenho do atleta em várias provas de competição. O nosso objectivo inicial foi obstaculizado pelo contexto e especificidade das competições desportivas, nas quais as várias provas de competição, onde cada atleta participou, eram espaçadas por um curto espaço de 
tempo, não tendo sido possível a mensuração do desempenho do atleta após uma competição específica de experiência de fracasso (ou onde o desempenho real do atleta fosse abaixo do esperado). Com efeito, o instrumento Grelha de Percepção de Desempenho para o Atleta trata-se de uma medida global e subjectiva, não captando com especificidade e objectividade o desempenho real que o atleta obteve em cada prova de competição desportiva. Assim, sugere-se para futuras investigações o desenvolvimento e a inclusão de uma medida objectiva do desempenho real do atleta. Ainda relativamente aos instrumentos, a avaliação da motivação para treinar/ competir por parte dos atletas pode ter sido respondida de modo irrealisticamente alto, existindo também a possibilidade da escala não ser uma medida sensível do constructo que pretende medir (i.e. possíveis problemas na qualidade psicométrica da escala, especificamente a sua validade de conteúdo). Com efeito, esta limitação aplica-se especialmente ao estudo da motivação, o que pode contribuir para a dificuldade em retirar conclusões fidedignas relativamente aos resultados.

Como futuras linhas de pesquisa, seria ainda importante a replicação deste estudo com uma amostra maior, no sentido de dar maior consistência aos dados e análises, bem como comparar diferentes amostras, ao nível do sexo, idade, características da modalidade (por exemplo, escalão competitivo, experiência/ anos de prática, número de anos de competição, horas de treino por semana, competições por ano).

Apesar destas limitações, este estudo, tanto quanto é do nosso conhecimento, foi o primeiro em Portugal a utilizar os constuctos de aceitação/evitamento experiencial e auto-criticismo no domínio da Psicologia do Desporto.

\section{Referências bibliográficas}

Araújo, S., \& Gomes, A. R. (2005). Efeitos de um programa de controle de ansiedade e de visualização mental na melhoria de competências psicológicas em jovens atletas: Uma intervenção na natação. Psicologia: Teoria, Investigação e Prática, 2, 211-225.

Bandura, A. (1977). Social learning theory. Englewood Cliffs, NJ: Prentice-Hall.

Barbosa, L. G., \& Cruz, J. F. (1997). Estudo do stress, da ansiedade e das estratégias de confronto psicológico no andebol de alta competição. Psicologia: Teoria, Investigação e Prática, 3 (2), 523-548.

Costa, J., \& Pinto Gouveia, J. (2010). The mediation effect of experiential avoidance between coping and psychopathology in chronic pain. Clinical Psychology and Psychotherapy.

Cruz, J. F. (1996). Stress, ansiedade e rendimento na competição desportiva. Dissertação de Doutoramento. Universidade do Minho: Centro de Estudos em Educação e Psicologia.

Cruz, J. F., \& Barbosa, L. G. (1998). Stress, ansiedade e confronto psicológico na competição desportiva: Uma nova abordagem de natureza cognitiva, motivacional e relacional. Psicologia: Teoria, Investigação e Prática, 3, 021-070. 
Cruz, J. F., \& Viana, M. F. (1997). Escala de ansiedade no desporto: Características e validade da adaptação portuguesa. In J. Cruz \& A. R. Gomes (Eds.), Psicologia aplicada ao desporto e à actividade física. Braga: Universidade do Minho.

Cruz, J. F., Viveiros, M. L., Alves, L. A., Gomes, A. R., Matos, D., Ferreira, M. J., \& Dias, C. (2006). Características psicométricas de uma versão portuguesa do "Competitive State Anxiety Inventory-2" (CSAl-2): Dados preliminares relativos à sua validade e estrutura factorial. In N. Santos, M. Lima, M. Melo, A. Candeias, M. Grácio \& A. Calado (Eds.), Actas do VI Simpósio Nacional de Investigação em Psicologia (Vol. 3, pp. 104-125). Évora: Departamento de Psicologia, Universidade de Évora.

Feldner, M. T., Zvolensky, M. J., Eifert, G. H., \& Spira, A. P. (2003). Emotional avoidance: An experimental test of individual differences and response suppression during biological challenge. Behaviour Research and Therapy, 41, 403-411.

Follette, V. M., Palm, K. M., \& Hall, M. L. R. (2004). Acceptance, mindfulness, and trauma. In S. C. Hayes, V. M. Follette, M. M. Linehan (Eds.), Mindfulness and acceptance: Expanding the Cognitive-Behavioral Tradition (pp. 192-208). New York: The Guilford Press.

Gardner, F. L., \& Moore, Z. E. (2004). A mindfulness-acceptance-commitment-based approach to athletic performance enhancement: Theoretical considerations. Behavior Therapy, 35, 707-723.

Gilbert, P. (2000). Social mentalities: Internal 'social' conflict and the role of inner warmth and compassion in cognitive therapy. In P. Gilbert \& K. G. Bailey (Eds.), Genes on the couch: Explorations in evolutionary psychotherapy (pp. 118-150). Hove, UK: Brunner-Routledge.

Gilbert, P., \& Irons, C. (2004). A pilot exploration of the use of compassionate images in a group of self-critical people. Memory, 12, (4), 507-516.

Gilbert, P., \& Irons, C. (2005). Focused therapies and compassionate mind training for shame and self-attacking. In P. Gilbert (Ed.), Compassion: Conceptualization, research and use in psychotherapy (pp.263-320). Hove, UK: Routledge.

Gilbert, P., \& Procter, S. (2006). Compassionate mind training for people with high shame and self-criticism: Overview and pilot study of a group therapy approach. Clinical Psychology and Psychotherapy, 13, 353-379.

Gilbert, P., Baldwin, M. W., Irons, C., Baccus, J. R., \& Palmer, M. (2006). Self-criticism and self-warmth: An imagery study exploring their relation to depression. Journal of Cognitive Psychotherapy: An International Quarterly, 20, (2), 183-200.

Gilbert, P., Clarke, M., Hempel, S., Miles, J., \& Irons, C. (2004). Criticizing and reassuring oneself: An exploration of forms, styles and reasons in female students. The British Journal of Clinical Psychology, 43, 31-51.

Gilbert, P., Durrant, R., \& McEwan, K. (2006). Investigating relationships between perfectionism, forms and functions of self-criticism, and sensitivity to put-down. Personality and Individual Differences, 41, 1299-1308.

Gould, D., Jackson, S., \& Finch, L. (1993). Sources of stress in national champion figure skaters. Journal of Sport \& Exercise Psychology, 15, 134-159.

Gross, J. J., \& John, O. P. (2003). Individual differences in two emotion regulation processes: Implications for affect, relationships, and well-being. Journal of Personality and Social Psychology, 85, 348-362.

Hayes, S. C. (1994). Content, context, and types of psychological acceptance. In S. C. Hayes, N. S. Jacobson, V. M. Follette, \& M. J. Dougher (Eds.), Acceptance and change: Content and context in psychotherapy (pp. 13-32). Reno, NV: Context Press. 
Hayes, A. \& Feldman, G. (2004). Clarifying the construct of Mindfulness in the context of emotion regulation and the process if change in therapy. Clinical Psychology: Science and Practice, $11(3), 255-262$.

Hayes, S. C. \& Smith, S. (2005). Get out of your mind \& into your life: The new acceptance \& commitment therapy. Oakland: New Harbinger Publications.

Hayes, S. C., Strosahl, K., \& Wilson, K. G. (1999). Acceptance and commitment therapy: An experiential approach to behavior change. New York: The Guilford Press.

Hayes, S. C., Luoma, J. B., Bond, F. W., Masuda, A., \& Lillis, J. (2006). Acceptance and commitment therapy: Model, process and outcomes. Behaviour Research and Therapy, 44, 1-25.

Hayes, S. C., Strosahl, D. K., Bunting, K., Twohig, M., \& Wilson, G. K. (2004a). What is acceptance and commitment therapy? In Hayes, C. S., Strosahl, D. K. (Eds.). A practical guide to acceptance and commitment therapy (pp.3-21). New York: Springer.

Hayes, S. C., Strosahl, D. H., Wilson, K. G., Bissett, R. T., Pistorello, J., Toarmino, D., et al. (2004b). Measuring experiential avoidance: A preliminary test of a working model. The Psychological Record, 54, (4), 553-578.

John, O. P., \& Gross, J. J. (2004). Healthy and unhealthy emotion regulation: Personality processes, individual differences, and life span development. Journal of Personality, 72, 1301-1333.

Karekla, M., Forsyth, J. P., \& Kelly, M. M. (2004). Emotional avoidance and panicogenic responding to a biological challenge procedure. Behavior Therapy, 35, 725-746.

Kashdan, B. T., Barrios, V., Forsyth, P. J., \& Steger, F. M. (2006). Experiential avoidance as a generalized psychological vulnerability: Comparisons with coping and emotion regulation strategies. Behaviour Research and Therapy, 44, 1301-1320.

Mahoney, M. J., Gabriel, T. J., \& Perkins, T. S. (1987). Psychological skills and exceptional athletic performance. The Sport Psychologist, 1, 135-141.

Mairal, J. B. (2004). Spanish adaptation of the acceptance and action questionnaire (AAO). International Journal of Psychology and Psychological Therapy, 3, (4), 505-515.

Martens, R., Burton, D., Vealey, R., Smith, D., \& Bump, L. (1983). The development of the competitive state anxiety inventory-2. University of Urbana, Champaign-Illinois.

Pais-Ribeiro, J. L., Honrado, A., \& Leal, I. (2004). Contribuição para o estudo da adaptação portuguesa das escalas de ansiedade, depressão e stress (EADS) de 21 itens de Lovibond e Lovibond. Psicologia, Saúde \& Doenças, 5 (1), 229-239.

Pinto Gouveia, J., Gregório, S., Dinis, A., \& Xavier, A. (2011). Confirmatory factor analysis on the Portuguese version of Acceptance and Action Questionnaire (AAQ-II) - Psychological inflexibility in clinical and nonclinical samples. Manuscrito submetido para puclicação

Pestana, M. H., \& Gageiro, J. N. (2008). Análise de dados para ciências sociais: A complementaridade do SPSS (5 Edição). Lisboa: Edições Sílabo.

Segal, Z. V., Williams, J. M. G., \& Teasdale, J. D. (2002). Mindfulness-based cognitive therapy for depression. New York: The Guilford Press.

Spira, A. P., Zvolensky, M. J., Eifert, G. H., \& Feldner, M. T. (2004). Avoidance-oriented coping as a predictor of anxiety-based physical stress: A test using biological challenge. Journal of Anxiety Disorders, 18, 309-323.

Smith, R. E. (1986). Toward a cognitive-affective model of athletic burnout. Journal of Sport Psychology, 8, 36-50.

Whelan, J., Mahoney, M., \& Meyers, A. (1991). Performance enhancement in sport: A cognitivebehavioral domain. Behavior Therapy, 22, 307-327. 


\section{The (Un)Success in Sportive Competition: the influence of Acceptance and Self-Criticism.}

It has been empirically showed the importance of acceptance of private events (thoughts, emotions, sensations), especially those that are negatively evaluated. Acceptance can be important as a counter response to attempt change, avoid and control the affective and cognitive negative experiences, as well as self-criticism. The present study investigates, within a sample of 106 swimming athletes, the influence of acceptance and self-criticism in motivation of athletes for training and their depressive and anxiety symptomatology, at different moments of anticipation, during and reaction to the sportive competition.

Results clearly show that competitive anxiety is negatively related with acceptance and psychological skills. Furthermore, competitive anxiety is positively associated with self-criticism and the perception of a threat. Regression analysis shows that the acceptance is a unique contribution to competitive anxiety prediction; selfcriticism predicts the perception of a threat in sportive competition.

KEY-WORDS: Acceptance; Self-Criticism; Competitive Anxiety; Motivation.

\section{Le (non) succès dans le sport de compétition: l'influence de l'acceptation et de l'autocritique.}

Il a été empiriquement démontré l'importance de l'acceptation des événements privés (pensées, émotions, sensations), en particulier ceux qui sont évalués de façon négative. L'acceptation peut être importante comme une réponse aux tentatives contraire de modifier, d'éviter ou de contrôler les expériences négatives du point de vue cognitive et affective, ainsi que l'autocritique. Cette étude examine, dans un échantillon de 106 nageurs, l'influence de l'acceptation et de l'autocritique sur la motivation des athlètes et de l'anxiété et de dépression vécue à des moments différents de l'anticipation, pendant et de réaction à la compétition.

Les résultats montrent que l'anxiété compétitive est corrélée négativement avec l'acceptation et avec les compétences fonctionnelles pour le sport. De la même façon, l'anxiété compétitive a une corrélation positive avec l'autocritique et la perception de la menace générée par la compétition. Les analyses de régression montrent que l'acceptation est le meilleur pré-dicteur de l'anxiété compétitive; l'autocritique est le meilleur pré-dicteur de la perception de la menace générée par la compétition.

MOTS-CLÉS: Acceptation, Autocritique, Anxiété Compétitive, Motivation. 